\title{
An Inorganic Complex that Inhibits Mycobacterium tuberculosis Enoyl Reductase as a Prototype of a New Class of Chemotherapeutic Agents to Treat Tuberculosis
}

\author{
Luiz A. Basso, ${ }^{*, a, b}$ Cristopher Z. Schneider, ${ }^{a, b}$ Anderson J. A. B. dos Santos, ${ }^{a, b}$ \\ André A. dos Santos Jr, ${ }^{b, c}$ Maria M. Campos, ${ }^{b, c}$ André A. Souto ${ }^{a, b}$ and Diógenes S. Santos ${ }^{*, a, b}$ \\ ${ }^{a}$ Centro de Pesquisas em Biologia Molecular e Funcional (CPBMF), Tecnopuc, Prédio 92A, \\ ${ }^{b}$ Instituto Nacional de Ciência e Tecnologia em Tuberculose (INCT-TB), 'Instituto de Toxicologia, Prédio 12, \\ Pontifícia Universidade Católica do Rio Grande do Sul (PUCRS), Av. Ipiranga, 6681, Partenon, \\ 90619-900 Porto Alegre - RS, Brazil
}

\begin{abstract}
Descrevemos a atividade inibitória do IQG607, pentaciano(isoniazida)ferrato(II), frente a cepas de Mycobacterium tuberculosis tanto resistentes quanto sensíveis à isoniazida, assim como a toxicidade oral e a adaptação da síntese química do IQG607 para reatores maiores. O IQG607 representa um potencial agente quimioterápico que inibe um alvo molecular definido.
\end{abstract}

Here we describe the inhibitory activity of IQG607, pentacyano(isoniazid)ferrate(II), on isoniazid-sensitive and isoniazid-resistant strains of Mycobacterium tuberculosis, its oral toxicity, and efforts to adapt IQG607 synthesis to large chemical reactors. IQG607 represents a promising chemotherapeutic agent aiming at the inhibition of a validated and druggable molecular target.

Keywords: Mycobacterium tuberculosis, enoyl reductase, toxicology, large-scale synthesis, metallodrug

\section{Introduction}

Tuberculosis (TB) remains the leading cause of mortality due to a bacterial pathogen, Mycobacterium tuberculosis. ${ }^{1}$ In 2007, there were an estimated 9.27 million cases of $\mathrm{TB}$, and 1.37 million (15\%) were also HIV-positive patients, who are more likely to develop active TB. ${ }^{2}$ Brazil ranks $14^{\text {th }}$ in terms of the total number of incident cases amongst the high-burden countries. ${ }^{2}$ There were an estimated 0.5 million cases of multidrugresistant TB (MDR-TB), which is caused by strains resistant to, at least, isoniazid and rifampicin. ${ }^{2}$ The emergence of extensively drug-resistant (XDR) TB cases, which are found in TB-infected patients whose isolates are MDR and also resistant to a fluoroquinolone and, at least, one second-line injectable agent,,$^{2,3}$ its widespread distribution, ${ }^{4}$ and unprecedented fatality rate, ${ }^{5}$ raise the prospect of virtually incurable and deadly TB worldwide. The factors that most influence the emergence of drugresistant strains include inappropriate treatment regimens and patient noncompliance in completing the prescribed

*e-mail: luiz.basso@pucrs.br, diogenes@pucrs.br courses of therapy due to the lengthy standard "shortcourse" treatment (isoniazid, rifampicin, pyrazinamide, and ethambutol or streptomycin for two months, followed by a combination of isoniazid and rifampicin for additional four months) or when the side effects become unbearable. ${ }^{6}$ Moreover, no sustainable control of TB epidemic can be reached in any country without properly addressing this global public health problem, including research as a key component. ${ }^{7}$ M. tuberculosis has been considered the world's most successful pathogen, and this is largely due to the ability of the bacillum to persist in host tissues, where drugs that are rapidly bactericidal in vitro require prolonged administration to achieve comparable in vivo effects. ${ }^{8}$ Hence, more effective and less toxic anti-tubercular agents are immediately needed to shorten the duration of current treatment, improve the treatment of drug-resistant TB, and to provide effective treatment of latent TB infection.

The modern approach in the development of new chemical entities (NCEs) against TB is based on the use of defined molecular targets. This involves $(i)$ the search and identification of lead compounds with known molecular mechanisms against a specific target (e.g. enzymes from defined pathways), (ii) the analysis of compounds with a 
favorable cost/benefit ratio, (iii) the development, even in the initial stages, of compounds with selective toxicity (the fundamental principle of chemotherapy), (iv) the preclinical evaluation of lead compounds, $(v)$ the execution of clinical trials, and ( $v i)$ the generation of patents and the possibility of technology transfer.

The mycobacterial cell wall is comprised of three covalently linked macromolecules: peptidoglycan, arabinogalactan, and mycolic acid. ${ }^{9,10}$ Mycolic acids are high-molecular-weight $\alpha$-alkyl, $\beta$-hydroxy fatty acids, which appear mostly as bound esters in tetramycolylpentaarabinosyl clusters in the mycobacterial cell wall. The condensation, $\beta$-keto reduction, dehydration, and enoyl reduction chemical reactions of fatty acid elongation are catalyzed by two types of fatty acid synthase (FAS) systems. FAS-I system is a multidomain-single-polypeptide protein that catalyzes these chemical reactions, which is present in most eukaryotes, except in plants. On the other hand, FAS-II systems, which are present in bacteria and plants, catalyze the individual chemical reactions by separate proteins readily purified independently of the other enzymes of the pathway and are encoded by unique genes. ${ }^{11}$ Mycobacteria, unlike most organisms, have both FAS-I and FAS-II systems. ${ }^{10}$

The product of the M. tuberculosis inhA gene (InhA) has been shown to be a major target for isoniazid (INH, isonicotinic acid hydrazide), the most prescribed drug for active TB infection and prophylaxis. ${ }^{12}$ InhA was identified as an NADH-dependent enoyl-ACP (acyl carrier protein) reductase enzyme, which exhibits specificity for long-chain $\left(\mathrm{C}_{18}>\mathrm{C}_{16}\right)$ enoyl thioester substrates. ${ }^{13}$ InhA is a member of the mycobacterial FAS-II system, which elongates acyl fatty acid precursors yielding the long carbon chain of the meromycolate branch of mycolic acids, the hallmark of mycobacteria. ${ }^{10}$ Consistent with InhA being a target for $\mathrm{INH}$, mutations in the inhA structural gene were identified in INH-resistant clinical isolates of M. tuberculosis. ${ }^{14}$ More recently, it was shown by specialized linkage transduction that the introduction of inhA (S94A) point mutation in M. tuberculosis confers clinically relevant levels of resistance to INH killing and inhibition of mycolic acid biosynthesis. ${ }^{15}$

INH is a pro-drug that is activated by the mycobacterial KatG-encoded catalase-peroxidase enzyme in the presence of manganese ions, $\mathrm{NAD}(\mathrm{H})$, and oxygen. ${ }^{16}$ The KatGproduced acylpyridine fragment of isoniazid is covalently attached to the $\mathrm{C} 4$ position of NADH, and this isonicotinyl$\mathrm{NAD}^{+}$adduct forms a binary complex with InhA,${ }^{17}$ which is a slow, tight-binding competitive inhibitor with an overall dissociation constant $\left(\mathrm{K}_{\mathrm{i}}^{*}\right)$ value of $0.75 \times 10^{-9} \mathrm{~mol} \mathrm{~L}^{-1} .^{18}$

In trying to find better alternatives to $\mathrm{INH}$, we have investigated INH analogs that contain a cyanoferrate moiety. An example of this class of chemical compound is the pentacyano(isoniazid)ferrate(II) complex $\left(\mathrm{Na}_{3}\left[\mathrm{Fe}^{\mathrm{II}}(\mathrm{CN})_{5}(\mathrm{inh})\right] \cdot 3 \mathrm{H}_{2} \mathrm{O}\right)$, which hereby, for short, is referred to as IQG607 (Figure 1). Chemical synthesis and characterization of IQG607 have been reported elsewhere. ${ }^{19}$ We have shown that IQG607 inhibits enzyme activity of both INH-sensitive wild-type (WT) InhA and I21V mutant InhA identified in INH-resistant clinical isolates of M. tuberculosis. ${ }^{20}$ Inactivation experiments demonstrate that the inhibition is time-dependent. Incubation of WT InhA with IQG607 in the absence of NADH resulted in the time-dependent inactivation of the enzyme with an apparent first-order rate constant value of $327( \pm 34) \times 10^{-3} \mathrm{~min}^{-1}$, showing that this inorganic complex requires no activation by mycobacterial KatG, thus overcoming a major mechanism of resistance to INH.

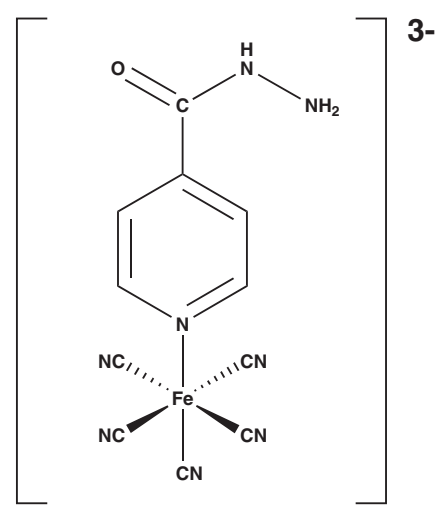

Figure 1. Structural formula of pentacyano(isoniazid)ferrate(II) complex, $\left[\mathrm{Fe}^{\mathrm{II}}(\mathrm{CN})_{5}(\mathrm{inh})\right]^{3-}$, referred to as IQG607.

The minimum inhibitory concentration (MIC) of IQG607 was radiometrically determined for the $M$. tuberculosis $\mathrm{H} 37 \mathrm{Rv}$ reference strain, displaying a value of $0.2 \mu \mathrm{g} \mathrm{mL} \mathrm{L}^{-1}$, which is comparable to the MIC value for INH (0.02-0.2 $\mu \mathrm{g} \mathrm{mL}-1){ }^{20}$ Preliminary toxicity assays in HL60 leukemia and MCS-7 breast cancer cells yielded an $\mathrm{IC}_{50}$ value $>25 \mu \mathrm{g} \mathrm{mL}^{-1} .^{20} \mathrm{As}$ suggested by the Tuberculosis Antimicrobial Acquisition \& Coordinating Facility of USA, for a compound to move forward through screening programs, its selectivity index (SI) values should be larger than 10 . The good selectivity index of IQG607 ( $\mathrm{SI}=\mathrm{IC}_{50} / \mathrm{MIC}>125$ ) thus warranted further efforts to be pursued. Accordingly, we have also shown that the IQG607 compound is a slow-onset inhibitor of M. tuberculosis InhA enzyme activity, with a true overall dissociation constant value of $70 \times 10^{-9} \mathrm{~mol} \mathrm{~L}^{-1}$. $^{21}$ In this mechanism of action an initial enzyme-inhibitor complex is rapidly formed, which then undergoes a slow isomerization reaction to an enzyme-inhibitor binary complex in which the inhibitor is more tightly bound to the enzyme. In addition, a half-time value of $630 \mathrm{~min}(10.5 \mathrm{~h})$ for the limiting step of inhibitor dissociation from the binary 
complex $\left(\mathrm{k}_{\text {off }}\right)$ was determined. ${ }^{21}$ More recently, we have shown that the IQG607 compound is a slow-onset inhibitor of INH-resistant I21V, S94A and I47T InhA mutants, with overall dissociation constant values similar to WT InhA. ${ }^{22}$ The IQG607 compound is stable in acidic medium $(\mathrm{pH} \leq 2.0)$ experimenting a reversible acid-base equilibrium of $\mathrm{CN}$ groups with a $\mathrm{pK}_{\mathrm{a}}=2.3,{ }^{20}$ which indicates that IQG607 has favourable characteristics to be orally administered, since it would not be degraded by the acidic $\mathrm{pH}$ of human digestive system, although additional pharmacokinetic experiments must be performed to confirm this proposition.

Here we briefly describe growth inhibition activity, oral toxicity studies, and efforts to adapt IQG607 chemical synthesis to large chemical reactors. The results show that IQG607 inhibits growth of both INH-sensitive and INHresistant strains of M. tuberculosis, and that it has a good safety profile as compared to INH. The results here presented demonstrate that IQG607 synthesis can be adapted to large scale production, which is particularly important because progression from basic research (milligrams) to pre-clinical pharmacological and toxicological studies (grams) and to, hopefully, clinical trials (kilograms), demands scaling up of IQG607 chemical synthesis.

\section{Experimental}

\section{Synthesis and characterization of IQG607}

The IQG607 complex was prepared by the direct reaction of $\mathrm{Na}_{3}\left[\mathrm{Fe}\left(\mathrm{CN}_{5}\right)\left(\mathrm{NH}_{3}\right)\right] \cdot 3 \mathrm{H}_{2} \mathrm{O}$ with isoniazid in aqueous solution at room temperature, and the compound was characterized by microanalysis, electronic, infrared, $500 \mathrm{MHz}{ }^{1} \mathrm{H}$ NMR and Mössbauer spectroscopies, and cyclic voltammetry as described. ${ }^{19-22}$ Here we briefly describe chemical synthesis of gram quantities of IQG607 that essentially is a scaled-up process of a previously one described in a PhD thesis supervised by Prof. Ícaro de Sousa Moreira of Inorganic and Organic Chemistry Department at Federal University of Ceará. ${ }^{23}$ All chemical reactions were carried out in a $500 \mathrm{~mL}$ jacketed-glass reactor at controlled temperature and stirring. For aminpentacyanoferrate(II) synthesis, $50 \mathrm{~g}(0.168 \mathrm{~mol})$ of sodium nitroprussiate were dissolved in $200 \mathrm{~mL}$ of $6 \mathrm{~mol} \mathrm{~L}^{-1}$ ammonium solution at constant stirring. $\mathrm{NH}_{3}$ gas was bubbled into the reaction mixture for $10 \mathrm{~h}$, at temperatures ranging from -1 to $-2{ }^{\circ} \mathrm{C}$. After reaction completion, a yellow solid was formed which was filtered and washed with absolute ethanol, yielding approximately $60 \%$ of product that was stored in a desiccator under vaccum. The synthesis of $\left[\mathrm{Fe}^{\mathrm{II}}(\mathrm{CN})_{5}(\mathrm{inh})\right]^{3-}$ complex (IQG607) employed a 1:3 metal/ligand molar ratio (0.061/0.183 mol) using $20 \mathrm{~g}$ of aminpentacyanoferrate(II) and $25.1 \mathrm{~g}$ of INH, which were dissolved in a volume of distilled water up to complete solubilization (minimum volume). The reaction was carried out under $\operatorname{argon}$ for $2 \mathrm{~h}$ at room temperature. The reaction product was precipitated in a $\mathrm{NaI}$ saturated solution in absolute ethanol, forming an orange-yellowish solid that was filtered and stored under vacuum in a desiccator protected from light, yielding $91 \%$ of IQG607. The identity of IQG607 synthesized in the $500 \mathrm{~mL}$ jacketed-glass reactor was confirmed by infrared and $400 \mathrm{MHz}{ }^{1} \mathrm{H}$ NMR spectroscopic analyses, as well as cyclic voltammetry studies. Results were consistent with characterization data presented previously. ${ }^{20-22}$

Determination of minimum inhibitory concentration (MIC) of IQG607 against INH-sensitive and INH-resistant strains of M. tuberculosis

MIC values for INH (control drug) and IQG607 (test) were determined by the colorimetric microplate resazurinbased Alamar Blue assay (MABA). ${ }^{24}$ The MIC was defined as the lowest drug (IQG607) concentration that prevented a color change from blue (no growth) to pink (growth) relative to untreated, drug-free cultures (control inoculum). INH and IQG607 growth inhibition activity was tested against the wild-type, INH-sensitive M. tuberculosis H37Rv (ATCC 27294) strain and two INH-resistant clinical isolates of $M$. tuberculosis, harboring mutations in the inhA structural (S94A) or in the inhA regulatory region $[\mathrm{C}(-15) \mathrm{T}] .{ }^{25}$ The mycobacterial strains were cultivated in Middlebrook 7H9 (Difco) liquid medium supplemented with 10\% (v/v) OADC (oleic acid, albumin, dextrose, catalase; Becton Dickinson) and $0.05 \%$ (m/v) Tween 80 (Sigma). Cultures were initially grown at $37^{\circ} \mathrm{C}$ up to an optical density of $c a .0 .4$ at $580 \mathrm{~nm}$. They were then diluted 1:50 in Middlebrook 7H9, and $100 \mu \mathrm{L}$ of M. tuberculosis inoculum were added to each well of the microplate. Final drug concentration ranges were 0.031 to $8.0 \mu \mathrm{g} \mathrm{mL}^{-1}$ for INH and 0.0625 to $16.0 \mu \mathrm{g} \mathrm{mL}^{-1}$ for IQG607. Results for all the tested M. tuberculosis strains were recorded after 5-7 days of incubation at $37^{\circ} \mathrm{C}$, and the MIC values reported here represent an average of three tests carried out independently. All these measurements were made employing a Biosafety Level 3 (BSL-3) containment facility available at CPBMF-PUCRS, which is a requirement for proper manipulation of biological agents that may cause serious or potentially lethal disease as a result of exposure by the inhalation route (such as M. tuberculosis).

\section{Acute oral toxicity}

The safety profile of IQG607 was assessed by means of acute toxicological assay in mice. For this purpose, 
both female and male Swiss mice (25 to $30 \mathrm{~g}$ ) were used. The animals were housed in groups of ten and maintained in controlled temperature $\left(22 \pm 2{ }^{\circ} \mathrm{C}\right)$ and humidity (60-70\%), under a $12 \mathrm{~h}$ light-dark cycle. Food and water were available ad libitum. The studies reported herein followed the "Principles of Laboratory Animal Care" from National Institute of Health (NIH) publication No. 85-23 and ethical guidelines for investigation of experimental pain in conscious animals. ${ }^{26}$ The Institutional Ethics Committee of PUCRS approved all the experimental procedures. The number of animals was the minimum necessary to demonstrate consistent effects for drug treatments. Different doses of IQG607 (250, 500, 1000 and $2000 \mathrm{mg} \mathrm{kg}^{-1}$ ) were orally administered to each ten mice per sex. Control animals received the vehicle $(0.9 \% \mathrm{NaCl}$ solution; $\left.10 \mathrm{~mL} \mathrm{~kg}^{-1}\right)$ by oral route. Isoniazid $\left(250 \mathrm{mg} \mathrm{kg}^{-1}\right.$, per os - p.o., meaning oral administration) was used as a positive control drug. Clinical symptoms, including mortality, were observed once a day for 15 days. Body weight was measured at the beginning of experiments and $3,6,9$, and 15 days after. At the end of the experimental period, the animals were euthanized and different organs (namely heart, spleen, liver, lungs and kidneys) were carefully dissected and their absolute weights (in grams) were determined.

\section{Results and Discussion}

\section{Scaling-up synthesis of IQG607}

The chemical synthesis protocol described above yielded $25.0 \mathrm{~g}$ of IQG607 from $20 \mathrm{~g}$ of aminpentacyanoferrate(II). Importantly, no change in temperature could be detected in the reactor, which often represents a limiting factor for large-scale production of a chemical compound. The results here described clearly demonstrate that IQG607 synthesis can be adapted to larger chemical reactors to produce gram quantities, which is an important step towards large-scale production needed for further toxicological assays, pre-clinical pharmacological studies and, hopefully, clinical trials.

\section{IQG607 susceptibility tests}

The two INH-resistant strains of M. tuberculosis employed in the IQG607 susceptibility assays harbored either an inhA structural gene mutation (S94A) or an inhA promoter region mutation [C(-15)T]. MIC values were $1.0 \mu \mathrm{g} \mathrm{mL}^{-1}$ for $\mathrm{S} 94 \mathrm{~A}$ and $4.0 \mu \mathrm{g} \mathrm{mL}^{-1}$ for [C(-15)T] INH-resistant mutants, and $0.25 \mu \mathrm{g} \mathrm{mL}^{-1}$ for INH-sensitive M. tuberculosis $\mathrm{H} 37 \mathrm{Rv}$ strain. The MIC values for these two INH-resistant strains were reported to be $\geq 16 \mu \mathrm{g} \mathrm{mL} \mathrm{L}^{-1} .{ }^{25}$ As the IQG607 compound needs no KatG activation and is effective against INH-resistant strains harboring structural gene and promoter region mutations, this compound appears to be a promising candidate to treat a large proportion of patients infected with INHresistant M. tuberculosis strains. However, it should be pointed out that the mechanism of action of INH is complex, as mutations in at least five different genes ( $k a t G$, inhA, ahpC, kasA, and $n d h$ ) have been found to correlate with INH resistance..$^{10}$ At any rate, the IQG607 M. tuberculosis growth inhibition correlates well with in vitro inhibitory activity against WT InhA enzyme ${ }^{21}$ and InhA mutant enzymes identified in INH-resistant clinical isolates of $M$. tuberculosis. ${ }^{22}$ Although we have not been able to obtain crystals to provide an experimental three-dimensional structure of InhA-IQG607 binary complex, results of docking simulations of IQG607 in the cofactor binding site of WT InhA crystal structure suggest that the inhibitor molecule may undergo small conformational changes after initial docking in the active site of WT InhA and that IQG607 preferentially occupies the pyrophosphate and nicotinamide sites in the $\mathrm{NAD}(\mathrm{H})$ binding site. ${ }^{21}$

\section{Acute oral toxicity}

In order to provide safety information on IQG607, oral acute toxicity assays were carried out in mice. Mortality, clinical signs, and body weights were measured for 15 days after the oral single administration of IQG607 (250, 500, 1000 and $\left.2000 \mathrm{mg} \mathrm{kg}^{-1}\right)$. The doses of $1000 \mathrm{mg} \mathrm{kg}^{-1}$ and $2000 \mathrm{mg} \mathrm{kg}^{-1}$ of IQG607 produced $50 \%$ and $90 \%$ of deaths, respectively, of both female and male mice. On the other hand, all of the female and male mice treated with IQG607, at the doses of 250 and $500 \mathrm{mg} \mathrm{kg}^{-1}$, p.o., did not show any mortality, whereas the positive control drug INH, at a $250 \mathrm{mg} \mathrm{kg}^{-1}$ dose, caused $80 \%$ of deaths. Interestingly, the oral dosage of IQG607 ( 250 and $500 \mathrm{mg} \mathrm{kg}^{-1}$, p.o.) did not cause any significant body weight loss in either female or male, and clinical signs of toxicity were minimal throughout the 15-day observation period. Finally, the single oral treatment with IQG607 at the level of 250 and $500 \mathrm{mg} \mathrm{kg}^{-1}$ was not associated with any significant change in the absolute weight of heart, spleen, liver, lungs or kidneys. According to assessment in the oral toxicity assay, it is possible to suggest that IQG607 presents a good safety profile, especially when compared to the classical antituberculosis drug INH. Nevertheless, repeated dose oral toxicity studies are still necessary to confirm this proposition. 


\section{Conclusions}

The weakness in the use of classical enzyme inhibitors as drugs for clinical conditions is that inhibition results in the upstream accumulation of the substrate for the enzyme, which may overcome the inhibition. By contrast, the build up of substrate cannot have any effect on the isomerization of enzyme-inhibitor complex typical of the slow-onset mechanism and hence reversal of the inhibition. ${ }^{27}$ Moreover, the low half-time value for the limiting step of inhibitor dissociation from the binary complex is a desirable feature since it may be expected to enhance inhibitor's effectiveness. ${ }^{28}$ It has recently been proposed by scientists at GlaxoSmithKline (USA) that measurement of the dissociative half-life is a crucial metric of compound optimization and could be a key indicator of in vivo duration of efficacy and target selectivity. ${ }^{29}$ The drug-target binary complex residence time is quantified by the dissociative half-life of the drugtarget binary complex $\left(\mathrm{k}_{\text {off }}\right)$. Accordingly, the low value of the half-life for IQG607 dissociation from the binary complex ( $\mathrm{k}_{\text {off }}=10.5 \mathrm{~h}$ as mentioned above) is a desirable feature for a chemical compound to move further in drug discovery efforts. IQG607 was demonstrated to have activity in a primary screen (hit), and its activity profile warrants further development. InhA is both a validated target because it has been shown both to play a vital role in M. tuberculosis growth and to be a "druggable protein" because it can be reached and influenced by a particular drug (isonicotinyl-NAD ${ }^{+}$adduct). The results presented in this work show that the IQG607 compound has growth inhibition activity against both INH-sensitive and INHresistant strains of $M$. tuberculosis, that it displays a promising profile in preliminary toxicological assays providing valuable information on its pharmacological safety, and that it is amenable to large scale production. These features indicate that IQG607 is a viable candidate for further pre-clinical studies, which will be needed for IQG607 to move further in the drug development process (including in vivo efficacy).

In summary, IQG607 represents a drug candidate of a new class of anti-TB compounds aiming at inhibition of a validated and druggable molecular target. In addition, IQG607 is effective against INH-resistant strains, and it has good selectivity index and favourable toxicological features. Importantly, IQG607 is amenable to large-scale production. However, it should be kept in mind that absorption, elimination, metabolization, and pharmacokinetics, together with toxicology, are the main causes of failure during drug development. ${ }^{30}$ Because of this, IQG607 must be verified further in a series of toxicological tests (acute and chronic), to be conducted in cell culture systems (in vitro toxicology), and rodent and non-rodent animal species (in vivo toxicology), and these studies should be extended to investigate its bioavailability, metabolism, and excretion.

\section{Acknowledgments}

This work was supported by National Institute of Science and Technology on Tuberculosis (Decit/SCTIE/ MS-MCT-CNPq-FNDCT-CAPES) and Millennium Initiative Program (CNPq), Brazil. Diógenes S. Santos also acknowledges a grant awarded by BNDES. Diógenes S. Santos (304051/1975-06), Luiz A. Basso (520182/99-5) and Maria M. Campos (306836/2007-6) are research career awardees of the National Council for Scientific and Technological Development of Brazil (CNPq). Cristopher Z. Schneider thanks a fellowship awarded by BNDES. We would also like to thank Márcia S. N. Silva and Maria O. Ribeiro for providing the two INH-resistant strains of M. tuberculosis employed in IQG607 susceptibility assays. Last but not least, all these efforts stem from insightful contributions of inorganic and organic chemists led by the late Prof. Ícaro de Sousa Moreira of Federal University of Ceará.

\section{References}

1. Harries, A. D.; Dye, C.; Ann. Trop. Med. Parasitol. 2006, 100, 415.

2. World Health Organization, Geneva, Switzerland, 2009; www.who.int/tb/publications/global_report/2009, accessed in December, 2009.

3. Centers for Disease Control and Prevention (CDC); $M M W R$ Morb. Mortal. Wkly. Rep. 2006, 55, 301.

4. Dorman, S. E.; Chaisson, R. E.; Nat. Med. 2007, 13, 295.

5. Singh, J. A.; Upshur, R.; Padayatchi, N.; PLoS Med. 2007, 4, e50.

6. Mitchison, D. A.; Tubercle 1985, 66, 219; Duncan, K.; Tuberculosis 2003, 83, 201.

7. http://www.stoptb.org/researchmovement/areas.asp, accessed in November, 2009.

8. Hingley-Wilson, S. M.; Sambandamurthy, V.K.; Jacobs, W.R.Jr.; Nat. Immunol. 2003, 4, 949.

9. Brennan, P. J.; Nikaido, H.; Annu. Rev. Biochem. 1995, 64, 29.

10. Schroeder, E. K.; de Souza, O. N.; Santos, D. S., Blanchard, J. S.; Basso, L.A.; Curr. Pharm. Biotechnol. 2002, 3, 197; Basso, L.A.; Santos, D.S.; Med. Chem. Rev. Online 2005, 2, 393.

11. Cronan, J. E.; Rock, C. O. In Escherichia coli and Salmonella: Cellular and Molecular Biology; Neidhardt, F. C., ed., ASM Press: Washington, 1996, ch. 37. 
12. Banerjee, A.; Dubnau, E.; Quémard, A.; Balasubramanian, V.; Um, K. S.; Wilson, T.; Collins, D.; de Lisle, G.; Jacobs, W. R. Jr.; Science 1994, 263, 227.

13. Quémard, A.; Sacchettini, J. C.; Dessen, A.; Vilchèze, C.; Bittman, R.; Jacobs, W. R. Jr.; Blanchard, J. S.; Biochemistry 1995, 34, 8235 .

14. Basso, L. A.; Zheng, R.; Musser, J. M.; Jacobs, W. R. Jr.; Blanchard, J. S.; J. Infect. Dis. 1998, 178, 769.

15. Vilchèze, C.; Wang, F.; Arai, M.; Hazbón, M. H.; Colangeli, R.; Kremer, L.; Weisbrod, T. R.; Alland, D.; Sacchettini, J. C.; Jacobs, W. R. Jr.; Nat. Med. 2006, 12, 1027.

16. Johnsson, K.; King, D. S.; Schultz, P. G.; J. Am. Chem. Soc. 1995, 117, 5009; Johnsson, K.; Schultz, P. G.; J. Am.Chem. Soc. 1994, 116, 7425; Basso, L. A.; Zheng, R.; Blanchard, J. S.; J. Am. Chem. Soc. 1996, 118, 11301; Zabinski, R. F.; Blanchard, J. S.; J. Am. Chem. Soc. 1997, 119, 2331.

17. Rozwarski, D. A.; Grant, G. A.; Barton, D. H. R.; Jacobs, W. R. Jr.; Sacchettini, J. C.; Science 1998, 279, 98.

18. Rawat, R.; Whitty, A.; Tonge, P. J.; Proc. Natl. Acad. Sci. USA 2003, 100, 13881.

19. Moreira, I. S.; Franco, D. G.; Inorg. Chem. 1994, 33, 1607; Moreira, I. S.; Lima, J. B.; Franco, D. W.; Coord. Chem. Rev. 2000, 196, 197; Sousa, E. H. S.; Pontes, D. L.; Diógenes, I. C. N.; Lopes, L. G. F.; Oliveira, J. S.; Basso, L. A.; Santos, D. S.; Moreira, I. S.; J. Inorg. Biochem. 2005, 99, 368.

20. Oliveira, J. S.; Sousa, E. H. S.; Basso, L. A.; Palaci, M.; Dietze, R.; Santos, D. S.; Moreira, I. S.; Chem. Commun. 2004, 3, 312.
21. Oliveira, J. S.; Sousa, E. H. S.; de Souza, O. N.; Moreira, I. S.; Santos, D. S.; Basso, L. A.; Curr. Pharm. Des. 2006, 12, 2409.

22. Vasconcelos, I. B.; Meyer, E.; Sales F. A. M.; Moreira, I. S.; Basso, L. A.; Santos, D. S.; Anti-Infect. Agents Med. Chem. 2008, 7, 50 .

23. Sousa, E. H. S.; PhD Thesis, Universidade Federal do Ceará, Brazil, 2004.

24. Franzblau, S. G.; Witzig, R. S.; McLaughlin, J. C.; Torres, P.; Madico, G.; Hernandez, A.; Degnan, M. T.; Cook, M. B.; Quenzer, V. K.; Ferguson, R. M.; Gilman, R. H.; J. Clin. Microbiol. 1998, 36, 362.

25. Silva, M. S.; Senna, S. G.; Ribeiro, M. O.; Valim, A.R.; Telles, M.A.; Kritski, A. L.; Morlock, G. P.; Cooksey, R. C.; Zaha, A.; Rossetti, M. L.; J. Clin. Microbiol. 2003, 41, 4471.

26. Zimmermann, M.; Pain 1983, 16, 109.

27. Morrison, J. F.; Walsh, C. T.; Adv. Enzymol. Relat. Areas Mol. Biol. 1988, 61, 201.

28. Schloss, J. V.; Acc. Chem. Res. 1988, 21, 348.

29. Copeland, R. A.; Pompliano, D. L.; Meek, T. D.; Nat. Rev. Drug Discovery 2006, 5, 730; Tummino, P. J.; Copeland, R. A.; Biochemistry 2008, 47, 5481.

30. Greaves, P.; Williams, A.; Eve, M.; Nat. Rev. Drug Discovery 2004, 3, 226.

Received: August 14, 2009 Web Release Date: March 4, 2010 